\title{
GAMBARAN STATUS KARIES PADA ANAK BERKEBUTUHAN KHUSUS DI SLB YPAC MANADO
}

\author{
${ }^{1}$ Gita J. Tulangow \\ ${ }^{2}$ Damajanty H. C. Pangemanan \\ ${ }^{3}$ Wulan G. Parengkuan
}

\author{
${ }^{1}$ Kandidat Skripsi Program Studi Pendidikan Dokter Gigi Fakultas Kedokteran \\ ${ }^{2}$ Bagian Fisiologi Fakultas Kedokteran \\ ${ }^{3}$ Program Studi Pendidikan Dokter GigiFakultas Kedokteran Universitas Sam Ratulangi \\ Email: gitatulangow@gmail.com
}

\begin{abstract}
Dental caries is the most commonly oral disease found in all layers of society, including children with special needs. Some researchers mentioned that high rates of dental caries in children with special needs such as hearing impairment, physical impairment, and mental impairment were caused by their limitation in doing their daily activities. This study aimed to determine the status of dental caries in children with special needs. The index commonly used to access the status of caries is DMF-T. Samples were children with special needs aged 12-17 years old in SLB YPAC Manado. There were 36 children as samples obtained by using the total sampling method. The results showed that the caries status of children with special needs in SLB YPAC Manado with an average DMF-T index 4.4 was in middle category.
\end{abstract}

Keywords:caries status, children with special needs, DMF-T

\begin{abstract}
Abstrak: Karies gigi merupakan penyakit gigi dan mulut yang sering ditemukan di seluruh lapisan masyarakat termasuk pada anak berkebutuhan khusus. Beberapa penelitian menyebutkan bahwa tingginya angka karies gigi pada anak berkebutuhan khusus seperti tunarungu, tunadaksa dan tunagrahita, disebabkan karena mereka memiliki keterbatasan dalam melakukan aktivitas sehari-hari. Penelitian ini bertujuan untuk mengetahui bagaimana gambaran status karies gigi pada anak berkebutuhan khusus. Indeks yang umum digunakan untuk menilai status karies ialah indeks DMF-T. Penelitian ini dilakukan pada anak berkebutuhan khusus umur 12-17 tahun di SLB YPAC Manado dengan jumlah sampel sebanyak 36 siswa. Teknik pengambilan sampel menggunakan metode total sampel. Hasil penelitian menunjukkan status karies gigi pada anak berkebutuhan khusus di SLB YPAC Manado dengan indeks DMF-T sebesar 4,4 termasuk kategori sedang.
\end{abstract}

Kata kunci: status karies, anak berkebutuhan khusus, DMF-T

Masalah penyakit gigi dan mulut masih banyakdiderita masyarakat bahkan anakanak sampai saat ini yaitu penyakitkaries gigi. Karies gigimerupakan suatu penyakit jaringan keras gigi yang disebabkan oleh aktivitas suatu jasad renik dalam suatu karbohidrat yang dapat diragikan dan dapat terjadi jika ada beberapa faktor (Host, Mikroorganisme, Substrat) yang saling mendukung untuk proses terjadinya dengan waktu yang cukup. ${ }^{1}$

Terjadi peningkatan prevalensi karies yang cukup besar pada masyarakat di Indonesia, diantaranya juga pada anak usia sekolah yang merupakan satukelompok yang rentan terhadap penyakit gigi dan mulut. Peraturan Menteri Kesehatan Republik Indonesia Nomor25 tahun 2014 tentang upaya 
kesehatan anak menetapkan bahwa anak usia sekolah adalah anak umur lebih dari 6 tahun sampai sebelum berusia 18 tahun dan remaja adalah kelompok usia 10 tahun sampai berusia 18 tahun. $^{2}$

Anak berkebutuhan khusus (ABK) yaitu anak dengan keterbatasan fisik dan mental yang memiliki keterbatasan kondisi fisik perkembangan, tingkah laku atau emosi. Hal ini menyebabkan terjadinya gangguan fungsi fisiologis, psikologis atau struktur anatomi berkurang atau hilang, sehingga tidak dapat menjalankan aktifitas kehidupan sehari-hari secara normal yang mengakibatkan perubahan dalam alam pikiran, alam perasaan dan perbuatan. ${ }^{3}$

Masalah sosial pada anak berkebutuhan khusus memengaruhi kebutuhan pendidikan anak-anak tersebut sehingga memiliki pengetahuan yang masih kurang khususnya pengetahuan di bidang kesehatan. Pengetahuan tentang cara memelihara kesehatan gigi yang rendah mendukung tingginya angka karies pada anak berkebutuhan khusus. ${ }^{4}$ Oleh karena itu, anak berkebutuhan khusus memerlukan jenis pelayanan kesehatan lebih dari yang dibutuhkan oleh anak normal secara umum.

Keberadaan anak berkebutuhan khusus termasuk penyandangcacat secaranasional maupun sebarannya padamasing-masing provinsi belum memiliki datayang pasti. ${ }^{5}$ Pada tahun 2009, Badan Pusat Statistik (BPS) menyajikan datastatistik disabilitas dalam SUSENAS 2009 dengan kategori kecacatan denganjumlah total adalah 2.126.998 jiwa di Indonesia. ${ }^{5}$

Dalam jurnal yang berjudul Toothbrushing Intervention Programme Among Children With Mental Handicap menyebutkan bahwa kebersihan gigi dan mulut serta penyakitperiodontal merupakan masalah terbesar yang dialami penyandang cacat. ${ }^{6}$ Berdasarkan alasan-alasan tersebut maka penulis ingin meneliti bagaimana status karies gigi pada anak berkebutuhan khusus.

\section{METODE PENELITIAN}

Penelitian ini merupakan penelitian deskriptif untuk menggambarkan status karies pada anak berkebutuhan khusus. Penelitian ini dilaksanakan pada bulan Juli 2015. Populasi penelitian ini yaitu anak berkebutuhan khusus di SLB YPAC Manado dengan jumlah 49 anak. Metode pengambilan sampel yang digunakan yaitu total sampling. Terdapat 36 anak yang sesuai kriteria inklusi.

Variabel penelitian ini yaitu status karies dan anak berkebutuhan khusus (ABK). Pengukuran karies dihitung dengan menggunakan Indeks DMF-T (Decayed missing filling teeth) untuk gigi permanen. Indeks DMF-T ialah indeks yang digunakan pada gigi permanen untuk menunjukkan banyaknya gigi yang terkena karies. Kategori DMF-T menurut WHO yaitu; sangat rendah $(0,0-1,1)$, rendah $(1,2-$ $2,6)$, sedang $(2,7-4,4)$, tinggi $(4,5-6,5)$, sangat tinggi $(>6,6) .^{7}$ Data penelitian ini diolah dan dideskripsikan berdasarkan distribusi frekuensi dalam bentuk tabel, kemudian disajikan berdasarkan hasil persentase.

\section{HASIL PENELITIAN}

Hasil penelitian menunjukkan distribusi frekuensi responden dengan karakteristik yang dapat dilihat pada Tabel 1-10.

\section{BAHASAN}

Hasil pemeriksaan status karies gigi menunjukkan bahwa DMF-T pada anak berkebutuhan khusus memiliki skor DMF$\mathrm{T}$ kategori sedang 4,4 dan dari 36 responden, status karies gigi anak berkebutuhan khusus berada pada kategori sedang dengan persentase 83,3\%.

Hasil pemeriksaan status karies gigi menunjukkan bahwa DMF-T pada anak kelas tunarungu memiliki skor 3,5 kategori sedang dan status karies gigi anak kelas tunarungu ringan berada pada kategori sedang dengan persentase $100 \%$. Pada anak tunarungu sebanyak 10 orang, semuaya memiliki status karies sedang. Hasil penelitian ini sejalan dengan penelitian yang dilakukan Ayukawa $^{8}$ di Nunavik Canada, bahwa hampir semua siswa tunarungu memiliki karies pada gigi. 
Jurnal e-GiGi (eG), Volume 3, Nomor 2, Juli-Desember 2015

Tabel 1. Distribusi ABK berdasarkan umur dan jenis kelamin

\begin{tabular}{|c|c|c|c|c|c|c|c|c|c|c|c|c|c|c|}
\hline \multirow{3}{*}{$\begin{array}{c}\text { Jenis } \\
\text { Kelamin }\end{array}$} & \multicolumn{14}{|c|}{ Umur (tahun) } \\
\hline & \multicolumn{2}{|c|}{12} & \multicolumn{2}{|c|}{13} & \multicolumn{2}{|c|}{14} & \multicolumn{2}{|c|}{15} & \multicolumn{2}{|c|}{16} & \multicolumn{2}{|c|}{17} & \multicolumn{2}{|c|}{ Total } \\
\hline & $\mathrm{n}$ & $\%$ & $\mathrm{n}$ & $\%$ & $\mathrm{n}$ & $\%$ & $\mathrm{n}$ & $\%$ & $\mathrm{n}$ & $\%$ & $\mathrm{n}$ & $\%$ & $\mathrm{n}$ & $\%$ \\
\hline Lak & 9 & 34,5 & 6 & 23,7 & 3 & 11,8 & 2 & 7,2 & 1 & 3,6 & 5 & 19,1 & 26 & 72,2 \\
\hline Perer & 3 & 30 & 1 & 10 & 2 & 20 & 3 & 30 & 0 & 0 & 1 & 10 & 10 & 27,8 \\
\hline Jumlah & 12 & 33,3 & 7 & 19,4 & 5 & 13,9 & 5 & 13,9 & 1 & 2,8 & 6 & 16,7 & 36 & 100 \\
\hline
\end{tabular}

Hasil pemeriksaan karies gigi dapat dilihat sebagai berikut:

Tabel 2. Distribusi masing-masing komponen DMF-T ABK

\begin{tabular}{cccccc}
\hline \multirow{2}{*}{$\begin{array}{c}\text { Anak berkebutuhan } \\
\text { khusus }\end{array}$} & \multicolumn{3}{c}{ Komponen } & \multirow{2}{*}{ Skor } & Kategori \\
\cline { 2 - 4 } & $\mathrm{D}$ & $\mathrm{M}$ & $\mathrm{F}$ & & \\
\hline Tunarungu & 26 & 8 & 1 & 3,5 & Sedang \\
Tunadaksa & 59 & 8 & 0 & 6,7 & Sangat Tinggi \\
Tunagrahita & 40 & 18 & 0 & 3,6 & Sedang \\
Jumlah & 125 & 34 & 1 & 4,4 & Sedang \\
\hline
\end{tabular}

Tabel 3. Distribusi status karies gigi ABK

\begin{tabular}{ccc}
\hline Status karies & $\mathrm{n}$ & $\%$ \\
\hline Sangat rendah & 0 & 0 \\
Rendah & 0 & 0 \\
Sedang & 30 & 83,3 \\
Tinggi & 2 & 5,6 \\
Sangat tinggi & 4 & 11,1 \\
Jumlah & 36 & 100 \\
\hline
\end{tabular}

Tabel 4.Distribusi masing-masing komponen DMF-T berdasarkan kelas tunarungu

\begin{tabular}{cccccc}
\hline \multirow{2}{*}{ Tunarungu } & \multicolumn{3}{c}{ Komponen } & Skor & Kategori \\
\hline Ringan & 26 & M & F & & \\
Sedang & 0 & 0 & 0 & 3,5 & Sedang \\
Berat & 0 & 0 & 0 & - & - \\
Jumlah & 26 & 8 & 1 & 3,5 & - \\
\hline
\end{tabular}

Tabel 5.Distribusi masing-masing komponen DMF-T berdasarkan kelas tunadaksa

\begin{tabular}{cccccc}
\hline \multirow{2}{*}{ Tunadaksa } & \multicolumn{3}{c}{ Komponen } & Skor & Kategori \\
& $\mathrm{D}$ & $\mathrm{M}$ & $\mathrm{F}$ & & Sangat tinggi \\
Ringan & 59 & 8 & 0 & 6,7 & - \\
Sedang & 0 & 0 & 0 & - & - \\
Berat & 0 & 0 & 0 & - & Sangat tinggi \\
Jumlah & 59 & 8 & 0 & 6,7 & \\
\hline
\end{tabular}


Tulangow, Pangemanan, Parengkuan: Gambaran status karies...

Tabel 6. Distribusi status karies ABK berdasarkan kelas tunadaksa

\begin{tabular}{|c|c|c|c|c|c|c|c|c|c|c|c|c|}
\hline \multirow{3}{*}{ Tunadaksa } & \multicolumn{12}{|c|}{ Status karies } \\
\hline & \multicolumn{2}{|c|}{$\begin{array}{l}\text { Sangat } \\
\text { rendah }\end{array}$} & \multicolumn{2}{|c|}{ Rendah } & \multicolumn{2}{|c|}{ Sedang } & \multicolumn{2}{|c|}{ Tinggi } & \multicolumn{2}{|c|}{$\begin{array}{l}\text { Sangat } \\
\text { tinggi }\end{array}$} & \multicolumn{2}{|c|}{ Total } \\
\hline & $\mathrm{n}$ & $\%$ & $\mathrm{n}$ & $\%$ & $\mathrm{n}$ & $\%$ & $\mathrm{n}$ & $\%$ & $\mathrm{n}$ & $\%$ & $\mathrm{n}$ & $\%$ \\
\hline Ringan & 0 & 0 & 0 & 0 & 5 & 50 & 1 & 10 & 4 & 40 & 10 & 100 \\
\hline Sedang & 0 & 0 & 0 & 0 & 0 & 0 & 0 & 0 & 0 & 0 & 0 & 0 \\
\hline Berat & 0 & 0 & 0 & 0 & 0 & 0 & 0 & 0 & 0 & 0 & 0 & 0 \\
\hline Jumlah & 0 & 0 & 0 & 0 & 5 & 50 & 1 & 10 & 4 & 40 & 10 & 100 \\
\hline
\end{tabular}

Tabel 7. Distribusi masing-masing komponen DMF-T berdasarkan kelas tunagrahita

\begin{tabular}{cccccc}
\hline \multirow{2}{*}{ Tunagrahita } & \multicolumn{3}{c}{ Komponen } & Skor & Kategori \\
& $\mathrm{D}$ & $\mathrm{M}$ & $\mathrm{F}$ & & Sedang \\
Ringan & 22 & 7 & 0 & 3,6 & Sedang \\
Sedang & 18 & 11 & 0 & 3,6 & - \\
Berat & 0 & 0 & 0 & - & Sedang \\
Jumlah & 40 & 18 & 0 & 3,6 & \\
\hline
\end{tabular}

Tabel 8. Distribusi status karies ABK berdasarkan kelas tunagrahita

\begin{tabular}{ccccccccccccc}
\hline & \multicolumn{11}{c}{ Status karies } \\
\cline { 2 - 13 } Tunagrahita & $\begin{array}{c}\text { Sangat } \\
\text { rendah }\end{array}$ & Rendah & Sedang & Tinggi & $\begin{array}{c}\text { Sangat } \\
\text { tinggi }\end{array}$ & Total \\
\cline { 2 - 15 } & $\mathrm{n}$ & $\%$ & $\mathrm{n}$ & $\%$ & $\mathrm{n}$ & $\%$ & $\mathrm{n}$ & $\%$ & $\mathrm{n}$ & $\%$ & $\mathrm{n}$ & $\%$ \\
\hline Ringan & 0 & 0 & 0 & 0 & 8 & 100 & 0 & 0 & 0 & 0 & 8 & 50 \\
Sedang & 0 & 0 & 0 & 0 & 7 & 87,5 & 1 & 12,5 & 0 & 0 & 8 & 50 \\
Berat & 0 & 0 & 0 & 0 & 0 & 0 & 0 & 0 & 0 & 0 & 0 & 0 \\
Jumlah & 0 & 0 & 0 & 0 & 15 & 93,5 & 1 & 6,5 & 0 & 0 & 16 & 100 \\
\hline
\end{tabular}

Tabel 9. Distribusi status karies gigi ABK berdasarkan umur

\begin{tabular}{|c|c|c|c|c|c|c|c|c|c|c|c|c|}
\hline \multirow{3}{*}{$\begin{array}{l}\text { Umur } \\
\text { (tahun) }\end{array}$} & \multicolumn{12}{|c|}{ Status karies } \\
\hline & \multicolumn{2}{|c|}{$\begin{array}{l}\text { Sangat } \\
\text { Rendah }\end{array}$} & \multicolumn{2}{|c|}{ Rendah } & \multicolumn{2}{|c|}{ Sedang } & \multicolumn{2}{|c|}{ Tinggi } & \multicolumn{2}{|c|}{$\begin{array}{c}\text { Sangat } \\
\text { tinggi }\end{array}$} & \multicolumn{2}{|c|}{ Total } \\
\hline & $\mathrm{n}$ & $\%$ & $\mathrm{n}$ & $\%$ & $\mathrm{n}$ & $\%$ & $\mathrm{n}$ & $\%$ & $\mathrm{n}$ & $\%$ & $\mathrm{n}$ & $\%$ \\
\hline 12 & 0 & 0 & 0 & 0 & 9 & 75 & 2 & 16,7 & 1 & 8,3 & 12 & 100 \\
\hline 13 & 0 & 0 & 0 & 0 & 6 & 85,6 & 0 & 0 & 1 & 14,4 & 7 & 100 \\
\hline 14 & 0 & 0 & 0 & 0 & 5 & 100 & 0 & 0 & 0 & 0 & 5 & 100 \\
\hline 15 & 0 & 0 & 0 & 0 & 5 & 100 & 0 & 0 & 0 & 0 & 5 & 100 \\
\hline 16 & 0 & 0 & 0 & 0 & 1 & 100 & 0 & 0 & 0 & 0 & 1 & 100 \\
\hline 17 & 0 & 0 & 0 & 0 & 4 & 66,7 & 0 & 0 & 2 & 33,3 & 6 & 100 \\
\hline Jumlah & 0 & 0 & 0 & 0 & 30 & 83,3 & 2 & 5,6 & 4 & 11,1 & 36 & 100 \\
\hline
\end{tabular}

Tabel 10. Distribusi status karies gigi ABK berdasarkan jenis kelamin

\begin{tabular}{ccccccccccccc}
\hline \multirow{2}{*}{$\begin{array}{c}\text { Jenis } \\
\text { Kelamin }\end{array}$} & $\begin{array}{c}\text { Sangat } \\
\text { rendah }\end{array}$ & Rendah & Sedang & Tinggi & $\begin{array}{c}\text { Sangat } \\
\text { tinggi }\end{array}$ & \multicolumn{2}{c}{ Total } \\
\cline { 2 - 19 } & $\mathrm{n}$ & $\%$ & $\mathrm{n}$ & $\%$ & $\mathrm{n}$ & $\%$ & $\mathrm{n}$ & $\%$ & $\mathrm{n}$ & $\%$ & $\mathrm{n}$ & $\%$ \\
\hline Laki-laki & 0 & 0 & 0 & 0 & 21 & 80,7 & 1 & 3,8 & 4 & 15,5 & 26 & 72,2 \\
Perempuan & 0 & 0 & 0 & 0 & 9 & 90 & 1 & 10 & 0 & 0 & 10 & 27,8 \\
Jumlah & 0 & 0 & 0 & 0 & 30 & 83,3 & 2 & 5,6 & 4 & 11,1 & 36 & 100 \\
\hline
\end{tabular}


Aktivitas karies yang tinggi pada anak berkebutuhan khusus terjadi karena mereka mengalami kesulitan dalam menjaga oral hygiene, lemahnya otot serta rendahnya kemampuan untuk menggerakkan otot mulut yang berpengaruh terhadap prosedur rutindalam membersihkan gigi. ${ }^{8}$

Hasil pemeriksaan status karies gigi menunjukkan bahwa DMF-T pada anak kelas tunadaksa memiliki skor 6,7 kategori sangat tinggi dan pada tabel 7 , status karies sedang dimiliki oleh anak kelas tunadaksa ringan dengan persentase $50 \%$, sedangkan status karies sangat tinggi dimiliki oleh anak kelas tunadaksa ringan dengan persentase $40 \%$. Dalam penelitian ini tingkat gangguan pada tunadaksa yang ringan memiliki keterbatasan dalam melakukan aktivitas fisik tetapi masih dapat ditingkatkan melalui terapi karena memiliki gangguan gerak yang disebabkan oleh kelainan struktur tulang yang bersifat bawaan, sakit atau akibat kecelakaan. Menurut asumsi peneliti, resiko karies gigi pada anak tunadaksa dapat mengalami peningkatan dikarenakan beberapa anak masih bergantung pada orang lain. Anakanak dengan gangguan perkembangan masih belum memenuhi kebutuhan perawatan kesehatan gigi dan dianggap memiliki risiko lebih tinggi terhadap penyakit karies gigi daripada anak dengan perkembangan yang normal. ${ }^{9}$

Hasil pemeriksaan status karies gigi menunjukkan bahwa DMF-T pada anak kelas tunagrahita memiliki skor 3,6 kategori sedang dan status karies sedang dimiliki oleh anak kelas tunagrahita ringan sebanyak 8 orang dengan persentase $100 \%$, sedangkan pada anak kelas tunagrahita sedang dari 8 orang, status karies sedang dimiliki oleh anak tunagrahita sedang dengan persentase $87,5 \%$. Menurut asumsi peneliti, karies dapat terjadi pada anak tunagrahita karena memiliki keterkaitan dengan masalah medis yang merupakan suatu akibat dari beberapa penyakit atau kondisi yang tidak sempurna seperti akibat infeksi, gangguan metabolisme, penyakit otak yang nyata, kelainan kromosom, gangguan waktu kehamilan, dan masalah gigi atau rongga mulut yang dapat membahayakan kesehatan umum mereka. Hasil penelitian pada anak tunagrahita di Sekolah Dasar Luar Biasa C Dharma Wanita Persatuan Provinsi Kalimantan Selatan Banjarmasin menyatakan bahwa anak tunagrahita karena keterbatasannya sehingga tidak dapat mempertahankan kesehatan dan kebersihan mulutnya dengan baik. $^{10}$

Status karies sangat tinggi dimiliki oleh responden dengan umur 17 tahun dengan persentase 33,3\%. Menurut asumsi peneliti, karies dapat terjadi pada anak umur 17 tahun karena sejalan dengan pertambahan usia seseorang, jumlah karies akan bertambah karena memiliki jangka waktu yang lebih panjang untuk proses terjadinya karies.

Status karies sedang dimiliki oleh responden laki-laki dengan persentase $80,7 \%$ dan status karies sangat tinggi dengan persentase $15,5 \%$, hal ini terjadi karena menurut asumsi peneliti anak lakilaki kurang memperhatikan pemeliharaan kebersihan giginya sehingga tidak rajin menggosok gigi. Hal ini didukung oleh penelitian Petersen ${ }^{11}$ di bagian Selatan Thailand bahwa anak-anak perempuan lebih baik dalam perilaku menjaga kebersihan mulut dibandingkan dengan anak laki-laki. Penelitian yang sama dilakukan oleh Indry $^{12}$ di Manado, menunjukkan anak laki-laki memiliki ratarata DMF-T lebih tinggi daripada anak perempuan yaitu 3,86 dengan tingkat karies kategori sedang. Hal ini disebabkan lebih banyak anak perempuan yang memiliki kebiasaan menyikat gigi.

\section{SIMPULAN}

1. Status karies gigi anak berkebutuhan khusus di SLB YPAC Manado masuk dalam kategori sedang dengan indeks DMF-T 4,4.

2. Status karies gigi pada anak tunarungu di SLB YPAC Manado masuk dalam kategori sedang dengan indeks DMF-T 3,5 .

3. Status karies gigi pada anak tunadaksa di SLB YPAC Manado masuk dalam 
kategori sangat tinggi dengan indeks DMF-T 6,7.

4. Status karies gigi pada anak tunagrahita di SLB YPAC Manado masuk dalam kategori sedang dengan indeks DMF-T 3,6 .

\section{SARAN}

Berdasarkan hasil penelitian dan kesimpulan penelitian ini, maka dapat disarankan:

1. Bagi Pemerintah: Khususnya Dinas Kesehatan penulis menyarankan untuk meningkatkan program preventif dan promotif di bidang kesehatan gigi dan mulut untuk sekolah penyandang anak cacat.

2. Bagi Institusi Sekolah: Diharapkan agar lebih meningkatkan peran guru dalam memimpin program sikat gigi massal di sekolah dan memerhatikan kesehatan gigi serta mengajarkan cara merawat gigi dan mulut pada anak berkebutuhan khusus.

3. Bagi Orang Tua: Diharapkan dapat memberikan perhatian lebih serta contoh perilaku pemeliharaan kebersihan gigi dan mulut yang benar.

\section{DAFTAR PUSTAKA}

1. Kidd EAM, Bechal SJ. Dasar-dasar karies, penyakit dan penanggulangannya. Jakarta: EGC, 1991; p. 9.

2. Peraturan Menteri Kesehatan Republik Indonesia Nomor25 Tahun 2014. Upaya Kesehatan Anak, 2014; p. 3.

3. Pedoman Pelayanan Kesehatan Anak di Sekolah Luar Biasa (SLB). Direktorat Bina Kesehatan Anak Kementrian Kesehatan RI, 2010; p. 2.

4. Indahyani ED, et al. Kelompok Anak-anak Berkebutuhan Khusus. Jember: Universitas Jember, 2012; p. 2.

5. Simarmata SG. Pusat Perawatan Anak
Berkebutuhan Khusus. Medan: Universitas Sumatra Utara, 2013; p. 2.

6. Stefanovska E, Nakova M, RadojkovaNikolovska V, Ristoska S. ToothBrushing Intervention Programme Among Children WithMental Handicap [clinical study], 2010.

7. Departemen Kesehatan R.I. Direktorat Jendral Pelayanan Medik, Direktorat Kesehatan Gigi; Profil Kesehatan Gigi dan Mulut di Indonesia Pada Pelita VI. Jakarta,1999; p.17-69.

8. Ayukawa H, et al. Hearing Loss and Dental Health. Institut National de Sante Publique. 2007. Available from: www.inspq.qc.ca/pdf/publications/65 9_esi_hearing_loss.pdf.

9. National Institute of Dental and Craniofacial Research. Practical Oral are for People withCerebral Palsy. Bethesda, 2009. NIH publication no 09-5192.

10.Azzahra NN, Wasilah S, Aspriyanto D. Indeks Kebersihan Rongga Mulut pada Anak Retardasi Mental Tinjauan pada Sekolah Dasar Luar Biasa (SDLB) C Dharma Wanita Persatuan Provinsi Kalimantan Selatan Banjarmasin. Banjarmasin. Program Studi Kedokteran Gigi Fakultas Kedokteran Universitas Lambung Mangkurat. Jurnal Kedokteran Gigi. 2014;II(1):79.

11.Petersen PE. Oral Health Behavior of Urban and Rural Schoolchildren in Southern Thailand. International Dental Journal. 2001;51:95-102.

12.Saima A, Saleem M, Mohtada H, Fatima I. Distribution of dental caries and its relationship to risk factors. Pakistan oral \& dental journal. 2011:31(2): 453-56. Available from: http://www.podj.com.pk/Dec_2011/5 2-Podj.pdf. 